\title{
BMJ Open Disciplined doctors: Does the sex of a doctor matter? A cross-sectional study examining the association between a doctor's sex and receiving sanctions against their medical registration
}

\author{
Emily Unwin, Katherine Woolf, Clare Wadlow, Jane Dacre
}

To cite: Unwin E, Woolf $\mathrm{K}$, Wadlow C, et al. Disciplined doctors: Does the sex of a doctor matter? A crosssectional study examining the association between a doctor's sex and receiving sanctions against their medical registration. $B M J$ Open 2014:4:e005405. doi:10.1136/bmjopen-2014005405

- Prepublication history for this paper is available online. To view these files please visit the journal online (http://dx.doi.org/10.1136/ bmjopen-2014-005405).

Received 9 April 2014 Revised 16 July 2014 Accepted 17 July 2014

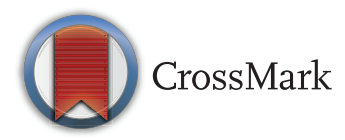

UCL Medical School, Royal Free Hospital, London, UK

Correspondence to Dr Emily Unwin; emily.unwin.12@ucl.ac.uk

\section{ABSTRACT}

Objectives: To examine the association between doctors' sex and receiving sanctions on their medical registration, while controlling for other potentially confounding variables.

Design: Cross-sectional study.

Setting: The General Medical Council (GMC)'s List of Registered Medical Practitioners (LRMP) database of doctors practising in the UK.

Population: All doctors on the GMC's LRMP on 29 May 2013. The database included all doctors who are or have been registered to practise medicine in the UK since October 2005. The exposure of interest was doctor's sex. Confounding variables included years since primary medical qualification, world region of primary medical qualification and specialty.

Outcome measures: Sanctions on a doctor's medical registration. Sanction types included warnings, undertakings, conditions, suspension or erasure from the register. Binary logistic regression modelling, controlling for confounders, described the association between the doctor's sex and sanctions on a doctor's medical registration.

Results: Of the 329542 doctors on the LRMP, $2697(0.8 \%)$ had sanctions against their registration, $516(19.1 \%)$ of whom were female. In the fully adjusted model, female doctors had nearly a third of the odds (OR: $0.37,95 \% \mathrm{Cl}: 0.33$ to 0.41 ) of having sanctions compared to male doctors. There was evidence that the association varies with specialty, with female doctors who had specialised as general practitioners being the least likely to receive sanctions compared with their male colleagues (OR: $0.26,95 \%$

Cl: 0.22 to 0.31 ).

Conclusions: Female doctors have reduced odds of receiving sanctions on their medical registration when compared with their male colleagues. This association remained after adjustment for the confounding factors. These results are representative of all doctors registered to practise in the UK. Further exploration of why doctors' sex may impact their professional performance is underway.

\section{Strengths and limitations of this study}

- We used a large national database with no missing data, so the findings of the study apply to all doctors registered to practise in the UK.

- Receiving sanctions is a rare outcome and using a large data set is crucial when examining rare outcomes.

- This is one of the first studies of this nature on UK data that adjusted for known confounders.

- The study was constrained by the variables collected and made available by the General Medical Council (GMC), so we were unable to examine the effect of other potential confounding factors.

- The data available did not provide the reasons why a sanction had been imposed, nor data on those granted voluntary erasure. A more detailed evaluation of the reasons for referral to the GMC may go towards explaining the sex difference observed.

\section{INTRODUCTION}

The number of complaints about doctors' fitness to practise received by the UK medical regulatory body, the General Medical Council (GMC), has been increasing since 2007. ${ }^{1}$ Following a triage and investigation process by the GMC, the outcome of a case against a doctor can be closed, or can result in a sanction against the doctor's registration. The cost of this regulatory process, not only in terms of the financial cost of the actual complaints investigation procedure, but also in terms of the loss of the medical workforce during the process, can be significant. The level of stress that a doctor endures while undergoing a fitness to practise investigation was recently reported in the $B M J$ and highlights the impact that the complaints investigation procedure can have on the mental well-being of doctors. ${ }^{2}$ 
One of the most significant changes in the medical profession has been the increase in the number of women entering this profession, previously a male-dominated profession. The number of female medical students has been increasing since the mid-1960s with female medical students outnumbering male medical students since the mid-1990s. ${ }^{3}$ It is predicted that female doctors will outnumber their male colleagues by 2017. ${ }^{3}$ This change in the demographic profile of UK doctors has brought with it a heightened interest in how the increase in female doctors may impact the profession.

Examining and understanding the predictors of doctors receiving sanctions may aid the medical profession in identifying doctors whose performance might raise future concerns, in order to support these doctors and help prevent GMC referral. Research from Canada, the USA and Australia and New Zealand has suggested that male and female doctors differ in terms of risk of disciplinary action, with male doctors being at increased risk. ${ }^{4-10}$ However, the applicability of the findings from these studies to the UK may be limited due to differences in the medical and legal systems in these countries. In 2011, Wakeford ${ }^{11}$ explored the situation in the UK. He examined the factors associated with the severest outcomes of the GMC disciplinary procedures, suspension or erasure from the medical register. In agreement with these worldwide studies, he demonstrated that female doctors were four times less likely to be disciplined when compared with male doctors. However, the interpretation of this finding is limited because the measure of effect for doctors' sex was not adjusted for potential confounders.

We aimed to examine the effect of doctors' sex on receiving sanctions against their medical registration, while adjusting for known confounding factors. This would allow for a meaningful comparison of male and female doctors and their experience of disciplinary action in the UK.

\section{METHODS}

\section{Study design, setting and source of data}

We conducted a cross-sectional study using UK-wide data. The data and permission to use the data for research purposes were obtained from the GMC.

Under the Medical Act 1983, the GMC is required to keep up-to-date registers of qualified doctors. The main register is the List of Registered Medical Practitioners (LRMP). The LRMP is a list of all doctors registered to practise medicine in the UK, and as such changes daily. It lists those doctors who are practising (or could practise) medicine, as well as those doctors who have been suspended or whose names have been erased from the medical register. The GMC provided us with a snapshot of doctors registered on the LRMP on 29 May 2013. The list included all doctors who have been registered with the GMC (and therefore eligible to actively practise medicine) at any point in the period 20 October $2005^{\mathrm{i}}$ to 28 May 2013. The different categories of registration status included provisionally or fully registered; suspended; not registered-administrative reason, or deceased, or having relinquished registration; and not registered-erased after Fitness to Practise panel hearing. The database provided details of the doctor's sex; the year, country and institutions of the doctor's primary medical qualification (PMQ) and the doctor's current registration status, including whether they currently had any sanctions on their medical registration (see below for details). It classified doctors as general practitioners (GPs) (on the GP register) and as hospital specialists (on the specialist register). For inclusion on the GP or specialist register, a doctor must be a fully qualified consultant or GP (ie, the doctor must have successfully completed their Specialty Training). Doctors who are neither on the GP nor specialist register can be primarily divided into two groups: the first being doctors who are currently undertaking a specialty training programme with the aim of becoming a GP or a consultant in a specialty, and the second group being composed of doctors in non-training posts. Non-training posts are for doctors who are not fully qualified consultants or GPs. Non-training posts are focused to meet the National Health Service (NHS) service requirements and the doctors who choose to undertake a non-training post do so for a variety of reasons including difficulty in obtaining a place in a specialty training programme due to the high competition, or doctors who prefer the work-life balance that the non-training post can provide. ${ }^{12}$

\section{Population}

All doctors who were listed on the LRMP on 29 May 2013 were included.

\section{Primary outcome and exposure}

The outcome of interest was sanctions on a doctor's medical registration on 29 May 2013.

The types of sanctions included:

- Warning: Issued when a doctor's performance has not been in keeping with the principles set by the GMC for doctors, but a restriction on the doctor's registration is not necessary. Warnings remain on the LRMP for a 5 -year period.

- Undertakings: An agreement between the GMC and the doctor about the doctor's future practice. The doctor must adhere to these undertakings to maintain their registration.

- Conditions: Set out by the GMC and restrict a doctor's practice. The doctor must comply with these conditions to maintain their registration. Conditions can

${ }^{\mathrm{i}}$ The 20th October 2005 was the date when the GMC first began to publish full details of a doctor's registration status on the LRMP online. 
initially be imposed for a maximum of 3 years and then be renewed in periods of up to 36 months.

- Suspension or erasure: The doctor's license is withdrawn by the GMC and they are no longer able to practise. Suspension from the register can last up to 12 months, but may be indefinite in certain circumstances.

A sanction can be imposed if a doctor's fitness to practise has been proved to be impaired. The impairment can result from misconduct, poor professional performance, physical or mental ill health, or a conviction or fitness to practise determination by another regulatory body either in the UK or overseas. ${ }^{13}$ However, it is recognised that the reason for impairment can cross more than one category (eg, a doctor with a drug misuse problem could be classified as having mental ill health, yet the effects of the drug abuse could impact their professional performance). The duration of a sanction on a doctor's registration varies and it is possible for doctors to have more than one sanction against their registration, and this typically represents the outcomes of different complaints (for further information on sanctions, visit http://www.gmc-uk.org/concerns/index.asp). It was not possible to establish the date a sanction was imposed or the reason why a sanction had been imposed from the available data.

The outcome of interest was collapsed into a binary variable: doctors with sanctions against their registration and doctors with no sanctions against their registration.

The exposure of interest was doctor's sex, as declared by the doctor to the GMC.

\section{Selection of variables}

The variables included in the study were selected before any statistical analysis. Data were available on the year of $\mathrm{PMQ}$ country of PMQ and primary specialty, if on the Specialist or General Practitioner (GP) Registers. These variables were selected as a priori confounders based on findings from earlier research, ${ }^{7} 811{ }^{14}$ which demonstrated that these factors may influence the risk of receiving sanctions.

Once the variables had been selected, we performed a variable reduction process, to reduce the number categories into meaningful categories. Once again, this was performed before any statistical analysis. The variable 'year of PMQ' was converted into 'number of years since qualification' by subtracting the year of PMQ from 2013. ${ }^{\text {ii }}$ We then collapsed the variable into six categories. The first category ' $0-2$ years' represented Foundation Training, whereas the second category ' $3-10$ years' represented the bulk of time a doctor would be likely to spend in Specialty Training. The subsequent categories

\footnotetext{
ii As mentioned above, a doctor could appear in the LRMP dataset if they had been removed from the medical register. The actual date of those doctors being removed could lie anytime between 20 October 2005 and 28 May 2013. However, as no actual removal dates were given for those doctors, we used 2013 for all doctors.
}

were divided into 10-year blocks. The variable 'country of PMQ' was collapsed into three categories: 'UK', 'EEA' (European Economic Area) and 'International'. The list of countries included in the EEA category was obtained from the European Union website ${ }^{15}$ and included all countries that were members before May 2013. The variable 'specialty' was divided into 14 categories. Doctors who were not present on either the Specialist Register or the GP Register were categorised as having 'no specialty' and represented trainee and other non-specialist doctors. Doctors on both the Specialist Register and the GP Register were recorded as having 'dual specialty' and doctors only on the GP register were categorised as 'GP'. For doctors only registered on the Specialist Register, their primary specialty was taken and recorded into 1 of 11 categories. To categorise those doctors on the Specialist Register, two researchers (EU and CW) independently allocated each primary specialty to a specialty category. The $\kappa$ statistic demonstrated a good level of agreement $(\kappa=0.72)$. Any disagreements about the specialty category allocation were resolved through discussion.

\section{Statistical methods}

We took a causal modelling analysis approach to analyse the data. We first performed bivariate analyses to look for crude associations in the data, followed by Mantel-Haenszel analyses, before going on to complete multivariate analyses using binary logistic regression modelling. The initial logistic regression model included only the exposure (sex) and outcome (sanctions) variables to provide a crude measure of effect. The final logistic regression model was built to include all potential confounder variables, while checking for multicollinearity. The final logistic regression model enabled the calculation of an adjusted measure of effect. The final model was assessed for the presence of effect modifiers following the findings from the Mantel-Haenszel analyses.

Statistical analyses were conducted using the software Stata V.12/SE.

We used the STROBE Statement ${ }^{16}$ to guide our study report.

\section{RESULTS}

There were 329542 doctors on the LRMP on 29 May 2013, of whom $40.3 \%$ were female. Table 1 shows the distribution of variables by the sex of doctors. The median number of years since qualification was 19 years. The distribution of the number of years since a doctor had qualified was skewed to the right with the majority of the doctors qualifying $11-20$ years ago (28.1\%). The majority of the doctors had received their PMQ from a UK medical school (59.3\%).

Approximately half of all the doctors were neither on the GP Register nor the Specialist Register $(51 \%)$, of which the majority (58\%) had received their PMQ 
Table 1 Distribution of variables by sex of doctors

\begin{tabular}{|c|c|c|c|}
\hline Variable & $\begin{array}{l}\text { Male } \\
\mathrm{N}=196814\end{array}$ & $\begin{array}{l}\text { Female } \\
\mathrm{N}=132728\end{array}$ & $\begin{array}{l}\text { Total } \\
\mathrm{N}=329542\end{array}$ \\
\hline \multicolumn{4}{|c|}{ Sanction imposed on registration } \\
\hline No & 194633 (98.9\%) & $132212(99.6 \%)$ & $326845(99.2 \%)$ \\
\hline Yes & $2181(1.1 \%)$ & $516(0.4 \%)$ & $2697(0.8 \%)$ \\
\hline \multicolumn{4}{|c|}{ Number of years since receipt of $P M Q$} \\
\hline $0-2$ & $6332(3.2 \%)$ & $8830(6.7 \%)$ & $15162(4.6 \%)$ \\
\hline $3-10$ & $28548(14.5 \%)$ & $37220(28.0 \%)$ & $65768(20.0 \%)$ \\
\hline $11-20$ & 52437 (26.6\%) & $40023(30.2 \%)$ & $92460(28.1 \%)$ \\
\hline $21-30$ & $39146(19.9 \%)$ & $23069(17.4 \%)$ & $62215(18.9 \%)$ \\
\hline $31-40$ & 30206 (15.4\%) & $12136(9.1 \%)$ & $42342(12.9 \%)$ \\
\hline$\geq 41$ & 40145 (20.4\%) & $11450(8.6 \%)$ & $51595(15.7 \%)$ \\
\hline \multicolumn{4}{|c|}{ Region where $P M Q$ received } \\
\hline UK & $108323(55.0 \%)$ & $86989(65.5 \%)$ & $195312(59.3 \%)$ \\
\hline EEA & 25333 (12.9\%) & $15880(12.0 \%)$ & $41213(12.5 \%)$ \\
\hline International & $63158(32.1 \%)$ & $29859(22.5 \%)$ & $93017(28.2 \%)$ \\
\hline \multicolumn{4}{|l|}{ Specialty } \\
\hline No specialty & $94815(48.2 \%)$ & $73309(55.2 \%)$ & $168124(51.0 \%)$ \\
\hline Anaesthetics & $8710(4.4 \%)$ & 3797 (2.9\%) & $12507(3.8 \%)$ \\
\hline EM & 754 (0.4\%) & 209 (0.2\%) & $963(0.3 \%)$ \\
\hline GP & $37959(19.3 \%)$ & $32264(24.3 \%)$ & $70223(21.3 \%)$ \\
\hline Medicine & $15076(7.7 \%)$ & $6775(5.1 \%)$ & $21851(6.6 \%)$ \\
\hline O\&G & 2934 (1.5\%) & $1966(1.5 \%)$ & 4900 (1.5\%) \\
\hline Ophthalmology & $2508(1.3 \%)$ & $1078(0.8 \%)$ & $3586(1.1 \%)$ \\
\hline Paediatrics & $3906(2.0 \%)$ & $3891(2.9 \%)$ & 7797 (2.4\%) \\
\hline Pathology & $5589(2.8 \%)$ & 2965 (2.2\%) & 8554 (2.6\%) \\
\hline Psychiatry & $5494(2.8 \%)$ & 3077 (2.3\%) & $8571(2.6 \%)$ \\
\hline Radiology & $172(0.1 \%)$ & $41(0.03 \%)$ & $213(0.1 \%)$ \\
\hline Surgery & 16452 (8.4\%) & 1942 (1.5\%) & 18394 (5.6\%) \\
\hline Other & $1330(0.7 \%)$ & 867 (0.7\%) & 2197 (0.7\%) \\
\hline Dual specialty & $1115(0.6 \%)$ & 547 (0.4\%) & $1662(0.5 \%)$ \\
\hline
\end{tabular}

EEA, European Economic Area; EM, emergency medicine; GP, general practice; O\&G, obstetrics and gynaecology; PMQ, primary medical qualification.

greater than 10 years previously. It is interesting to note that half of the doctors registered to practise medicine in the UK in this period were not registered specialists (they were neither on the GP nor Specialist register) and the majority of these doctors had qualified greater than 10 years ago, suggesting that these doctors are not trainee doctors, but doctors who have elected not to complete specialty training and are currently working in a non-training post. Of those doctors who had specialised, General Practice was the most popular specialty $(21.3 \%)$, followed by Medicine (6.6\%). Only $0.5 \%$ of the doctors were on both the Specialist and GP Registers.

In total, $2697(0.8 \%)$ doctors had sanctions against their registration on 29 May 2013. There was a higher proportion of male doctors who had sanctions against their registration when compared with female doctors (1.1\% of all male doctors compared with $0.4 \%$ of all female doctors, $\left.\chi^{2}=505.4, \mathrm{p}<0.001\right)$. There was strong evidence for an association between receiving sanctions and the number of years since receipt of PMQ with doctors who qualified 31-40 years ago having the highest proportion of sanctions; world region of PMQ with doctors who qualified outside the EEA with the highest proportion of doctors with sanctions; and specialty, with doctors on both the Specialist and GP Registers having the highest proportion of doctors with sanctions. These results are presented in table 2.

Using bivariate analyses, we compared female doctors with male doctors. There was a strong trend between the sex of a doctor and the number of years since the doctor received their PMQ, with female doctors being more likely to have recently qualified and the proportion of female doctors reducing as the number of years since PMQ increased. We also found that female doctors were more likely to have qualified in the UK $(65.5 \%$ of all female doctors compared with $55 \%$ of all male doctors) and male doctors were more likely to have qualified outside of the EEA $(32.1 \%$ of all male doctors compared with $22.5 \%$ of all female doctors). Approximately equal proportions of male and female doctors qualified in the EEA $(12.9 \%$ and $12 \%$, respectively). Both sexes were more likely to be not registered in a specialty (GP or hospital), though there was a slightly higher proportion of women when compared to men who were not on the Specialist or GP Register. 
Table 2 The distribution of sanctions for each variable and the association of individual factors with sanctions

\begin{tabular}{|c|c|c|c|}
\hline Variable & $\begin{array}{l}\text { Total } \\
\text { number of } \\
\text { doctors }\end{array}$ & $\begin{array}{l}\text { Sanctions } \\
(\%)\end{array}$ & $\begin{array}{l}p \\
\text { Value }\end{array}$ \\
\hline Sex & & & $<0.001$ \\
\hline Male & 196814 & 1.1 & \\
\hline Female & 132728 & 0.4 & \\
\hline $\begin{array}{l}\text { Number of years } \\
\text { since receipt of } \\
\text { PMQ }\end{array}$ & & & $<0.001$ \\
\hline $0-2$ & 15162 & 0.1 & \\
\hline $3-10$ & 65768 & 0.6 & \\
\hline $11-20$ & 92460 & 0.8 & \\
\hline $21-30$ & 62215 & 1.1 & \\
\hline $31-40$ & 42342 & 1.4 & \\
\hline$\geq 41$ & 51595 & 0.7 & \\
\hline $\begin{array}{l}\text { Region where PMQ } \\
\text { received }\end{array}$ & & & $<0.001$ \\
\hline UK & 195312 & 0.6 & \\
\hline EEA & 41213 & 0.9 & \\
\hline International & 93017 & 1.2 & \\
\hline Specialty & & & $<0.001$ \\
\hline No specialty & 168124 & 0.7 & \\
\hline Anaesthetics & 12507 & 0.7 & \\
\hline EM & 963 & 0.7 & \\
\hline GP & 70223 & 1.2 & \\
\hline Medicine & 21851 & 0.5 & \\
\hline $\mathrm{O} \& \mathrm{G}$ & 4,900 & 1.2 & \\
\hline Ophthalmology & 3,586 & 0.5 & \\
\hline Paediatrics & 7,797 & 0.6 & \\
\hline Pathology & 8,554 & 0.6 & \\
\hline Psychiatry & 8,571 & 0.8 & \\
\hline Radiology & 213 & 0.5 & \\
\hline Surgery & 18394 & 0.9 & \\
\hline Other & 2,197 & 0.3 & \\
\hline Dual specialty & 1,662 & 1.4 & \\
\hline
\end{tabular}

When examining those doctors who were registered in a specialty, a higher proportion of female doctors were on the GP Register compared with male doctors $(24.3 \%$ of female doctors compared with $19.3 \%$ of male doctors) and a higher proportion of male doctors were registered with a hospital specialty ( $32 \%$ of male doctors compared with $20.1 \%$ of female doctors).

In summary, number of years since receipt of PMQ, world region where PMQ was received, and registered specialty were associated with the outcome (sanctions) and the exposure (sex of a doctor) and as such we considered these variables as confounders.

The unadjusted OR for having sanctions against a doctor's registration comparing female doctors with male doctors was 0.35 (95\% CI 0.32 to 0.38 ), suggesting that being a female doctor is protective of receiving sanctions.
Table 3 The adjusted OR for having sanctions against registration for each variable compared to its baseline having adjusted for all other variables

\begin{tabular}{|c|c|c|c|}
\hline Variable & $\begin{array}{l}\text { Adjusted } \\
\text { OR }\end{array}$ & $95 \% \mathrm{Cl}$ & p Value \\
\hline Sex of a doctor & & & $<0.0001$ \\
\hline Male & 1 & & \\
\hline Female & 0.37 & 0.33 to 0.41 & \\
\hline $\begin{array}{l}\text { Number of years since } \\
\text { receipt of }\end{array}$ & & & $<0.0001$ \\
\hline $0-2$ & 1 & & \\
\hline $3-10$ & 3.42 & 2.20 to 5.32 & \\
\hline $11-20$ & 3.85 & 2.48 to 5.98 & \\
\hline $21-30$ & 5.66 & 3.63 to 8.81 & \\
\hline $31-40$ & 6.44 & 4.13 to 10.05 & \\
\hline$\geq 41$ & 3.12 & 1.20 to 4.87 & \\
\hline $\begin{array}{l}\text { Region where PMQ } \\
\text { received }\end{array}$ & & & $<0.0001$ \\
\hline UK & 1 & & \\
\hline EEA & 1.33 & 1.17 to 1.50 & \\
\hline International & 1.65 & 1.51 to 1.80 & \\
\hline Specialty & & & $<0.0001$ \\
\hline No specialty & 1 & & \\
\hline Anaesthetics & 0.65 & 0.52 to 0.82 & \\
\hline EM & 0.66 & 0.31 to 1.39 & \\
\hline $\mathrm{GP}$ & 1.43 & 1.29 to 1.58 & \\
\hline Medicine & 0.49 & 0.40 to 0.60 & \\
\hline O\&G & 1.22 & 0.93 to 1.59 & \\
\hline Ophthalmology & 0.53 & 0.33 to 0.83 & \\
\hline Paediatrics & 0.64 & 0.47 to 0.88 & \\
\hline Pathology & 0.65 & 0.50 to 0.86 & \\
\hline Psychiatry & 0.81 & 0.63 to 1.04 & \\
\hline Radiology & 0.47 & 0.07 to 3.38 & \\
\hline Surgery & 0.78 & 0.66 to 0.93 & \\
\hline Other & 0.36 & 0.17 to 0.77 & \\
\hline Dual specialty & 1.37 & 0.90 to 2.09 & \\
\hline
\end{tabular}

EEA, European Economic Area; EM, emergency medicine; GP, general practice; O\&G, obstetrics and gynaecology; $P M Q$, primary medical qualification.

Mantel-Haenszel analyses and tests of homogeneity were conducted to examine the change in the strength of the association between sanctions and sex while controlling for each of the confounders separately.

There was strong evidence that the true ORs were different between the different specialty categories ( $p=0.0002)$; therefore, specialty was considered as an effect modifier when conducting multivariate analyses.

Table 3 represents the results from the binary logistic regression model built to adjust for all the variables. After taking into account the number of years since $P M Q$ and world region where the doctor received their PMQ and specialty, female doctors had nearly a third of the odds of having sanctions on their registration compared with male doctors (OR: $0.37,95 \%$ CI: 0.33 to $0.41, \mathrm{p}<0.0001)$.

All of the a priori confounders were felt to be confounders because the adjusted OR changed when each variable was added to the model. We found no evidence of multicollinearity. 
The Mantel-Haenszel analyses suggested that specialty may be an effect modifier; we therefore performed a statistical test for effect modification by first collapsing the specialty variable into four groups to increase the power of the test. Table 4 demonstrates that specialty was felt to be an important effect modifier with female doctors being less likely to receive sanctions when compared with male doctors, but the effect was greater for GPs than for doctors with no specialty or those practising a hospital specialty.

\section{DISCUSSION}

In our large cross-sectional study, we found strong evidence that being female was associated with a reduction in odds of receiving sanctions (OR: $0.35,95 \%$ CI: 0.32 to 0.38 ) in the unadjusted model. Controlling for years since PMQ, world region where the doctor received their PMQ, and specialty did slightly increase this OR (OR: $0.37,95 \%$ CI: 0.33 to $0.41, \mathrm{p}<0.0001$ ), but there remained strong evidence for the association between doctor's sex and receiving sanctions. There was evidence that the association varied with specialty, with female GPs being the least likely to have sanctions against their registration.

To the best of our knowledge, this is the first study in the UK to examine the association between doctor's sex and receiving sanctions against medical registration, while adjusting for known confounders. We believe that these known confounders have only been adjusted for in one other study which was conducted in the USA. ${ }^{8}$

\section{Strengths and weaknesses of this study}

One of the major strengths of this study is that we used a large national database. The advantage of using this data set is twofold: first, since a national database was used, the findings of the study apply to all doctors registered to practise in the UK; second, receiving sanctions is a rare outcome and using a large data set is crucial when examining rare outcomes.

A further strength of this study is that it adjusted for known confounders; all these confounders have only been adjusted for in one previous study, which was conducted in California. ${ }^{8}$ Previous research on UK data did

\begin{tabular}{|c|c|c|c|}
\hline Variable & $\begin{array}{l}\text { Stratum- } \\
\text { specific OR }\end{array}$ & $95 \% \mathrm{Cl}$ & p Value \\
\hline Specialty category & & & $<0.0001$ \\
\hline No specialty & 0.43 & 0.38 to 0.49 & \\
\hline $\mathrm{GP}$ & 0.26 & 0.22 to 0.31 & \\
\hline Hospital specialty & 0.44 & 0.36 to 0.56 & \\
\hline Dual specialty & 0.09 & 0.13 to 0.70 & \\
\hline
\end{tabular}

not adjust the measure of effect of sex for potential confounders. $^{11}$

Finally, a further advantage was the completeness of the data set. The data are collected by the GMC for inclusion on the LRMP, and not research purposes. Doctors are required to provide the data to the GMC to be registered and as such there are no missing data. However, the fact the data are not collected for research purposes is also a limitation of the study. The study was constrained by the information collected and made available by the GMC. As such, we were only able to explore the variables available. We were unable to examine the effect of other potential confounding factors or explore the reasons why a sanction had been imposed; nor were we able to establish the date a sanction had been imposed.

It could be argued that the reason for referral to the GMC could be a source of residual confounding if systematic differences exist between the sexes. The GMC may take action against a doctor's registration for a number of reasons, which can be broadly divided into three major categories: misconduct, poor professional performance and physical or mental ill health. The data available did not provide the reasons or the category for why a sanction had been imposed, but a more detailed evaluation of the reasons for referral to the GMC may go towards explaining the sex difference observed. In their research, Alam et $a l^{4}$ and Elkin et $a l^{10}$ demonstrated not only that male doctors were more likely to be subject to disciplinary action, but also that the main offence for which a doctor was being disciplined was sexual misconduct. It is possible that male doctors are more likely to commit an offence involving sexual misconduct than their female colleagues, which may go towards explaining the sex difference seen in these populations. However, other studies in this area did not find sexual misconduct to be the most common offence. $^{679}$ As such, exploring the offences for which a doctor may receive disciplinary action in this population may go towards explaining the sex difference observed and may help the regulatory body and medical profession to introduce targeted interventions, such as education programmes, to reduce the number of offences.

A further source of residual confounding could be the route of referral. Doctors practising in the UK can be referred to the GMC through five main routes: the public, employers, doctors, the GMC and the police. ${ }^{17}$ It would be interesting to examine whether the referral rate for each route demonstrates any sex differences and, if so, exploring the reasons for this difference.

A further limitation is that a doctor can apply for voluntary erasure from the LRMP during an investigation process. Once again, this is a potential source of residual confounding and it is possible that the sex of doctors who are subject to a complaints investigation and apply for voluntary erasure differs from those doctors who complete the investigative process and receive a sanction (however, the GMC's decision to grant a request for 
voluntary erasure is based on the public interest and the doctor's health and likelihood to return to practise $\left.{ }^{18}\right)$. It is important to note that voluntary erasure is requested by doctors for multiple reasons other than being involved in an investigation process, including retiring permanently from practising medicine or leaving the UK to work permanently abroad. To explore whether voluntary erasure requests may explain the sex difference seen, the reason why a voluntary erasure request was submitted would first have to be ascertained. This information was not available in the data set used for this research, but could be requested and explored in future studies.

It is also of interest to note that certain sanctions (erasure and some suspensions) are permanent, whereas other sanctions are time limited. As such, the permanent sanctions may be over-represented because they will never be removed from a doctor's registration. If male doctors are more likely to receive these permanent sanctions, this could lead to male doctors being overrepresented when examining the association between sex and sanctions, and may go towards explaining the sex difference observed between doctors who had sanctions imposed against their registration.

Finally, a further limitation of the study is that nearly half of the doctors in the population were not recorded on the GP or Specialist register and were therefore classified as not having a specialty. Doctors who are not on the GP or Specialist Register typically fall into one of two categories: either a doctor who is on a Specialty Training programme with the aim of becoming a GP or a consultant in a specialty; or doctors who have chosen to work in a non-training post. It was not possible from the information made available by the GMC to examine these two categories. It would be of interest to explore if the proportions of male and female doctors differ in these two categories and to examine whether the risk of disciplinary action differs for doctors who are in a Specialty Training post compared with doctors who are working in a non-training post. It would also be of interest to explore if further information is available about the type of non-training post these doctors were working in and to examine the association with receiving sanctions.

\section{Comparison with other studies}

Our main finding, that female doctors are less likely to be subject to disciplinary action when compared with their male colleagues, mirrors the results of several studies from across the world, which have also examined the association between doctors' sex and disciplinary action. ${ }^{4-11}$ However, the majority of these studies have been performed in the USA, ${ }^{6-9}$ Canada, ${ }^{4}$ Australia and New Zealand, ${ }^{10}$ where the medical and legal systems differ from those of the UK, and therefore we felt that their findings may not be applicable to the UK population of doctors. These studies' main objective was not necessarily to explore the association between doctors' sex and disciplinary action. Some of these studies were descriptive and those studies that did control for confounders did not, albeit for one study, ${ }^{8}$ control for the same confounders we have selected. To the best of our knowledge, one study has been performed in the UK using national data ${ }^{11}$; however, when examining the association between doctors' sex and disciplinary action, this study did not control for any potential confounders.

The findings of this study are in agreement with previous research that has shown that older doctors, ${ }^{8}$ doctors who qualified outside of the country in which they are practising $^{11}{ }^{14}$ and doctors of certain specialties ${ }^{7}$ are more likely to be subjected to disciplinary action by a medical regulatory board. It has also been demonstrated in previous studies that female doctors are more likely to have qualified more recently than male doctors, ${ }^{3}$ are more likely to have qualified in the country in which they are practising ${ }^{19}$ and choose different specialties to male doctors. ${ }^{20}$

This study showed that the reason why male doctors receive more sanctions is not because they qualified earlier, nor because they are more likely to have qualified outside the UK, despite both of those factors being associated with increased likelihood of sanctions.

\section{Unanswered questions and future research}

This study has demonstrated that female doctors are less likely to receive sanctions against their medical registration compared with male doctors; however, it is not clear why women are less likely to receive sanctions when compared with men. Exploring the possible reasons for this sex difference in professional performance is required, using a theory-based approach. One theory suggested by some researchers is that male and female doctors differ in communication style, and hence the interaction with patients and colleagues differed between the sexes, which could affect the risk of being subject to a complaint. ${ }^{21}{ }^{22}$ Future research could be performed to explore this further and examine whether communication styles differ between male and female doctors, and also whether the communication styles of doctors who receive sanctions differ from doctors who have never received sanctions.

We have also demonstrated that the effect of sex on likelihood to receive sanctions varied by specialty, with female GPs being the least likely to receive sanctions. It has been demonstrated by an observational study of primary care physicians in the USA that female primary care physicians spend more time with their patients when compared with their male colleagues, and they engaged more in conversation, displaying more positivetalk, partnership-building, question-asking and information-giving. ${ }^{23}$ These differences in communication style and time spent with patients may go towards explaining the larger sex discrepancy observed in GPs; however, future research is required to explore these possible reasons further.

Our results show that doctors who had been qualified for longer were more likely to receive sanctions; it is 
therefore reasonable to hypothesise that the risk of receiving a sanction increases with exposure. Therefore, doctors who have fewer patient encounters may be less likely to receive sanctions against their registration. Previous studies have demonstrated that female consultants have fewer patient episodes and are more likely to work part-time (and thus have fewer patient encounters) when compared with their male colleagues; ${ }^{24} 25$ it is therefore reasonable to hypothesise that the sex difference observed in disciplinary action may be partly explained by the difference in work patterns between the sexes. This hypothesis merits being explored further by examining whether certain work patterns (ie, parttime compared with full-time work) are more likely to be associated with receiving sanctions.

A further possible explanation for the sex difference observed is perhaps that male and female doctors are viewed and treated differently by the public, the profession and the regulatory body. It is possible that there is a higher threshold of tolerance for female doctors. The GMC are twice as likely to receive a complaint about a male doctor than a female doctor. ${ }^{17}$ It is reasonable to assume that as a result male doctors are more likely to receive sanctions against their medical registration. Research examining the perception of male and female doctors would be warranted.

It should also be noted that this study was observational in design and as such causality cannot be determined. It is possible that other factors, such as ethnicity, may be confounding the association between doctors' sex and disciplinary action. Research examining whether other potential confounders could explain the observed association is required.

The points discussed above highlight that the real interest of this research is not about the outcome sanctions itself, but about trying to understand the differences between male and female doctors that lead to the observed sex difference in receiving sanctions. Investigations into why and how male and female medical practices differ will in turn lead to being able to propose interventions to reduce not only the number of doctors referred to the medical regulatory body, but also the difference between the sexes of doctors who are referred. Further exploration of why doctors' sex may impact their professional performance is needed to enable the profession to develop a better understanding of the factors associated with impaired fitness to practise and, crucially, how to better support those doctors and ensure patient safety.

\section{CONCLUSION}

In this study, we demonstrated that female doctors practising in the UK were less likely to receive sanctions on their medical registration when compared with their male colleagues. These findings remained after adjusting for known confounders. Reasons for why this sex difference exists need to be examined.
Acknowledgements The authors acknowledge Una Lane for facilitating access to the data and for answering our queries on the data set. They acknowledge Andrew Ledgard for clarifying their queries on the data set.

Contributors EU conceived and designed the study with input from KW and JD. EU and CW categorised the data. EU analysed and interpreted the data with support from KW. EU drafted the manuscript and all authors participated in the revision process and have approved this submission for publication. EU is the guarantor. She had full access to all of the data in the study, and take responsibility for the integrity of the data and the accuracy of the data analysis.

Funding This research received no specific grant from any funding agency in the public, commercial or not-for-profit sectors.

Competing interests EU is a PhD student and also a recipient of a UCL Impact studentship.

Ethics approval The study is part of a research project that has received ethical approval from the UCL Research Ethics Committee.

Provenance and peer review Not commissioned; externally peer reviewed.

Data sharing statement No additional data are available.

Open Access This is an Open Access article distributed in accordance with the Creative Commons Attribution Non Commercial (CC BY-NC 4.0) license, which permits others to distribute, remix, adapt, build upon this work noncommercially, and license their derivative works on different terms, provided the original work is properly cited and the use is non-commercial. See: http:// creativecommons.org/licenses/by-nc/4.0/

\section{REFERENCES}

1. General Medical Council. The state of medical education and practice in the UK. London: GMC, 2012.

2. Dyer C. GMC and vulnerable doctors: too blunt an instrument? BMJ 2013;347:f6230.

3. Elston MA. Women and medicine: the future. London: Royal College of Physicians, 2009.

4. Alam A, Klemensberg J, Griesman J, et al. The characteristics of physicians disciplined by professional colleges in Canada. Open Med 2011;5:e173-4.

5. Cardarelli R, Licciardone JC. Factors associated with high-severity disciplinary action by a state medical board: a Texas study of medical license revocation. JAOA 2006;106:153-6.

6. Clay SW, Conaster RR. Characteristics of physicians disciplined by the State Medical Board of Ohio. JAOA 2003;103:81-8.

7. Khaliq AA, Dimassi $\mathrm{H}$, Huang $\mathrm{CY}$, et al. Disciplinary action against physicians: who is likely to get disciplined? Am J Med 2005;118:773-7.

8. Kohatsu ND, Gould D, Ross LK, et al. Characteristics associated with physician discipline: a case-control study. Arch Intern Med 2004;164:653-8.

9. Morrison J, Wickersham P. Physicians disciplined by a State Medical Board. JAMA 1998;279:1889-93.

10. Elkin KJ, Spittal MJ, Elkin DJ, et al. Doctors disciplined for professional misconduct in Australia and New Zealand, 2000-2009. MJA 2011:194:452-6.

11. Wakeford R. Who gets struck off? BMJ 2011;343:d7842.

12. National Health Service-Medical Careers. Non-training posts. https://www.medicalcareers.nhs.uk/career_options/working_as_a_ doctor/non-training_posts.aspx (accessed Jul 2014).

13. General Medical Council. A guide for doctors referred to the GMC. http://www.gmc-uk.org/concerns/doctors_under_investigation/a_ guide_for_referred_doctors.asp (accessed Dec 2013).

14. Humphrey C, Hickman S, Gulliford MC. Place of medical qualification and outcomes of UK General Medical Council "fitness to practice" process: cohort study. BMJ 2011;342:d1817.

15. European Union. Countries. http://europa.eu/about-eu/countries/ index_en.htm (accessed May 2013).

16. Von Elm E, Altman DG, Egger M, et al. The Strengthening the Reporting of Observational Studies in Epidemiology (STROBE) Statement: Guidelines for reporting observational studies. PLoS Med 2007;4:e296.

17. General Medical Council. The state of medical education and practice in the UK. London: GMC, 2013. 
18. General Medical Council. Guidance on making decisions on voluntary erasure applications. GMC, 2013.

19. Lambert TW, Goldacre MJ, Parkhouse J. Doctors who qualified in the UK between 1974 and 1993: age, gender, nationality, marital status and family formation. Med Educ 1998;32:533-7.

20. Lambert TW, Goldacre MJ, Edwards C, et al. Career preferences of doctors who qualified in the United Kingdom in 1993 compared with those doctors qualifying in 1974, 1977, 1980, and 1983. BMJ 1996;313:19-24.

21. Taragin TI, Wilczek AP, Karns ME, et al. Physician demographics and the risk of medical malpractice. Am J Med 1992;93:537-42.
22. Firth-Cozens J. Doctors with difficulties: why so few women? Postgrad Med J 2008;84:318-20.

23. Roter D, Lipkin M, Korsgaard A. Sex differences in patients' and physicians' communication during primary care medical visits. Med Care 1991;29:1083-93.

24. Bloor K, Freemantle N, Maynard A. Gender and variation in activity rates of hospital consultants. J R Soc Med 2008;101: 27-33.

25. Goldacre MJ, Lambert TW, Davidson JM. Loss of British-trained doctors from the medical workforce in Great Britain. Med Educ 2001;35:337-44. 